\title{
Effect of Pelvic Floor Muscle Training on Urinary Incontinence in Gynecologic Cancer: A Review
}

\author{
Parivash Jamrasi ${ }^{1}$, Kyung-Hee Lee ${ }^{1}$, Wook Song ${ }^{1,2}$ \\ ${ }^{1}$ Health and Exercise Science Laboratory, Institute of Sport Science, Seoul National University, Seoul; '2Institute in Aging, Seoul National University, Seoul, Korea
}

PURPOSE: The purpose of this study is to investigate the applicability of pelvic floor muscle training to reduce urinary incontinence in gynecologic cancer patients based on positive evidences.

METHODS: This narrative review was conducted by searching terms in title or abstract such as 'pelvic floor muscle training', 'urinary incontinence' and 'gynecologic cancer' in PubMed, Google Scholar, SCOPUS, EBSCOHost, ScienceDirect, Cochrane Library and EMBASE databases which published from 2008 to 2018.

RESULTS: Studies mostly investigated the prevalence of urinary incontinence in cervical, ovarian and endometrial cancer patients. Seventy percent is the highest prevalence of urinary incontinence among gynecologic survivors that has reported so far. Pelvic floor muscle exercise for more than 4 weeks resulted in improved pelvic floor muscle strength. There was also a significant difference in the questionnaire related to improvement of pelvic floor function.

CONCLUSIONS: We suggest that pelvic floor muscle training may help to increase PFM strength and mitigate the symptom of urinary incontinence among patients with gynecologic cancer. However, further clinical research is required to evaluate the effectiveness of the pelvic floor muscle training on urinary incontinence symptoms in gynecologic cancers.

Key words: Gynecologic cancer, Urinary incontinence, Pelvic floor muscle training, Non-gynecologic cancer

\section{INTRODUCTION}

Gynecologic cancers, including the cervix, endometrium, fallopian tubes, ovaries, uterus, and vagina refers to the uncontrolled growth and spread of abnormal cells originating in the female reproductive tract. This cancer is one of top ten leading cancer types regarding estimated new cancer cases by sex. Approximately 98,280 (12.1\%) new cases were diagnosed as genital cancer in the United States [1] and 6,025 (5.9\%) cases were diagnosed as cervical, ovarian and endometrial cancers in South Korea [2] in 2015. According to the International Federation of Gynecology and Obstetrics (FIGO) staging systems, gynecologic cancer consists of four stages and subdivisions. The 5-year survival rate for gynecologic cancers by stage is detected as $89 \%, 66 \%, 34 \%$, and $18 \%$ respectively for Stage I, II, III, and IV [3]. The proportion of cancer survivors has been increased due to the advances of modern medicine. According to study the survival rate of gynecologic cancer patients will rise by $118 \%$ from 2016 to 2026 [4]. However, gynecologic cancer treatment including surgery, chemotherapy, and radiotherapy can give severe damage to pelvic floor muscles (PFM) that could make adverse effects such as pelvic floor dysfunction (PFD), lower extremity lymphedema, emotional concern and fatigue $[5,6]$. As a result, it became important to identify the adverse effects that frequently occur in the patient with gynecologic cancer and to find out an effective way to alleviate them.

PFM are located inside the pelvis consist of twelve striated muscles with three-layer muscular plate supporting pelvic organs such as urethra, vagina and rectum. During the cancer treatments, atrophy and length shortening may occur in PFM which may result PFD [7]. The symptoms of PFD are known as urinary incontinence (UI) and urgency, hematuria,

Corresponding author: Wook Song Tel +82-2-880-7791 Fax+82-2-872-2867 E-mail songw3asnu.ac.kr

Received 11 Oct 2018 Revised 4 Nov 2018 Accepted 18 Nov 2018

@) This is an Open Access article distributed under the terms of the Creative Commons Attribution Non-Commercial License (http://creativecommons.org/licenses/by-nc/4.0/) which permits unrestricted non-commercial use, distribution, and reproduction in any medium, provided the original work is properly cited. 
vaginal and rectal bleeding, dysuria, vaginal dryness and stenosis, dyspareunia and decreased sexual interest [8-11]. Among them, UI is closely related to PFD that can be recovered through pelvic floor muscle training (PFMT). According to the previous studies the PFMT program was effective treatment on women with stress, urge, and mixed urinary incontinence [12]. PFM plays an important role in preventing UI by tightening the urethra. Thus, PFMT may increase the strength of these muscles [13]. The PFMT introduced by Kegel in 1952 for the first time and over time different training protocols have been adopted to improve PFM function [14]. PFMT recognized as the mostly common nonsurgical treatment for UI, which is a physical training program consists of repetitive contraction of the PFM to improve strength and efficacy [15]. In overall, PFMT protocol contains fast contractions of PFM with a 3-second hold to improve strength and few repetitions of longer contractions up to 10 seconds holding with a goal of enhancement in muscle endurance. Though set and repetition of performance are various in studies, more than 3 sets of performance per day and 10 repetitions are often reported in the previous studies [16]. The PFMT program generally consists of contraction of the adductor muscles, sphincter tightening, and pelvic lifting. PFMT is basically doing by weight bearing, but also the resistance band or ball can be used to increase the exercise intensity. One study reported $84 \%$ of pa- tients were cured from UI by doing PFMT [14,17]. Although the effects of the training are well studied in women [18], men with prostate cancer patients [19-21], pregnant and postpartum women [22], yet, it has not been fully studied on gynecologic cancer patients. Therefore, the aim of this study is to identify UI type and incidence rate in the gynecologic cancer patient. Also, review the previous intervention studies that had a kinematics approach to improve UI symptom in non-cancer patients as studies are insufficient for gynecologic cancer. Finally, we investigate some of PFMT studies in the patient with gynecologic cancer to discuss the applicability of PFMT to reduce UI based on positive evidences.

\section{METHODS}

In this review article, we investigated studies through searching in the PubMed, Google Scholar, SCOPUS, EBSCOHost, ScienceDirect, Cochrane Library and EMBASE databases. We limited our search based on language (i.e., English), date of publication (i.e., since 2008 till 2018, last 10 years), the type of article (i.e., journal article), text availability (i.e., full text available) and focusing on previous literature which had the terms of "pelvic floor muscle training", "urinary incontinence" and "gynecologic cancer" in title or abstract. In primary search, those studies which reported
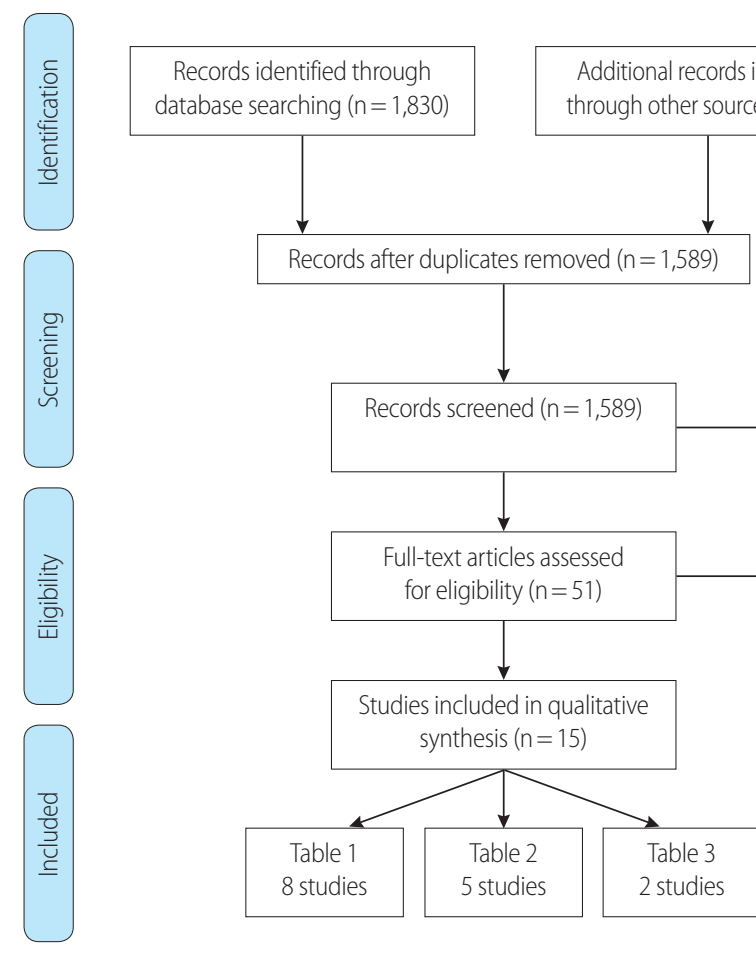

Records excluded ( $n=1,538)$

Irrelevant (987)

Old data (544)

Not in english (7)

Full-text articles excluded, with reasons $(n=36)$

Improper subject review (14)

No intervention (7)

No relation with UI (5)

No relation with gynecologic cancer (10)

Fig. 1. Flowchart of literature selection. 
the UI prevalence in gynecologic cancers such as Cervical, Ovarian, Uterine, Vaginal and Vulvar cancers were selected. The secondary selection of articles was limited to those studies which reported UI changes following PFMT either in gynecologic cancer patients or non-cancer patients. Articles were reviewed by two authors independently. At the end, after removing duplicates and non-relevant articles, a total of 15 articles met the criteria; 8 studies $(n=2,799)$ for investigating the UI prevalence among gynecologic cancer patients; 5 studies $(\mathrm{n}=444)$ in non-gynecologic cancer patients and 2 studies $(n=64)$ in gynecologic cancer patients which reported UI outcome after PFMT were selected for ongoing review (Fig. 1). In addition, we used PEDro scale to measure methodological quality of clinical trials.

\section{THE PREVALENCE OF URINARY INCONTINENCE}

Eight studies met the criteria for our studies which reported outcomes in association to UI including SUI and UUI. Most studies were designed in cohort and cross-sectional. Except for the two studies $[23,24]$ which reported the prevalence of UI before any treatment and surgery, the rest of studies reported outcomes after or during treatment (e.g., surgery, chemotherapy, radiation). The prevalence of UI in 2,423 survivors of major gynecologic cancers mostly cervical, endometrial and ovarian cancer before and after treatment is summarized in Table 1.

Of eight studies investigating UI, six studies used validated questionnaires. Bretschneider et al. [23] used International Consultation on Incontinence Questionnaire Female Lower Urinary Tract Symptoms Module (ICIQ-FLUTS) while Donovan et al. [25] used ICIQ-FLUTS along with Memorial Symptom Assessment Scale (MSAS). Rutledge et al. [26] and Skjeldestad et al. [27] used Sandvik Incontinence Severity Index. Hazewinkel et al. [10] used a set of a set of validated pelvic-floor-related quality of life questionnaires included the Uro-genital Distress Inventory (UDI) and the Defecatory Distress Inventory (DDI). Segal et al. [28] used Questionnaire for Urinary Incontinence Diagnosis (QUID) and Incontinence Severity Index questionnaire (ISI). Among gynecologic cancer patients SUI and UUI rates ranged from $30.8 \%$ [24] to $59.5 \%$ [23] and $13.9 \%$ [24] to $33.9 \%$ [23] before treatment, respectively. Among the gynecologic survivals, range of SUI reported from 24.3\% [27] to 76\% [25] while UUI reported from 9.3\% [27] to 75\% [25]. Regarding to type of treatment, Segal et al. investigated the effect of radiation therapy as a risk factor of pelvic floor function and reported 21.0\% SUI and 13\% UUI prevalent among "radiation therapy" group while 24.1\% SUI and 26.4\% UUI reported in "No radiation" group which concluded there is no association between radiation and urinary incontinence $(p>.05)$; whereas age $(\mathrm{aOR}=1.06,95 \%$ CI 1.02 1.10) and BMI (aOR=1.07, 95\% CI 1.02-1.11) significantly were observed as risk factors for UI. However, Hazewinkel et al. reported the result for each treatment group and conclude that patients who treated with radiotherapy as primary treatment more suffered of adverse effects on pelvic floor function rather than surgery with adjuvant radiotherapy or radical hysterectomy (57\% UUI [OR=3.7, 95\% CI 1.5-8.9] and 53\% SUI [OR=1.0, 95\% CI 0.5-2.4]). In Buchsbaum et al. [29] study that the prevalence of UI was similar among benign and malignant patients.

\section{PELVIC FLOOR MUSCLE TRAINING FOR THE NON-CANCER PATIENT WITH URINARY INCONTINENCE}

Five studies were selected to define the effect of PFMT in UI patients with non-gynecologic cancer. Castro et al. [30] reported that the effectiveness of PFMT was similar with other treatment such as electrical stimulation and vaginal cones based on objective and subjective evaluations. The treatments which include PFMT were far superior to no-treatment in women with SUI. However, high costs and the necessity of regular management were mentioned as the major concerns in various types of UI treatment, except for PFMT. In other study, symptoms of UI was significantly decreased in both SUI and UUI groups where home-based PFMT was conducted with no supervision [31]. Thus, PFMT might be a good alternative choice on UI patients. Besides, as the risk of developing gynecologic cancer is getting higher with ageing, PFqMT may be an appropriate exercise program for the elderly who are not free to go outsides, if adequate training is provided $[32,33]$. Two studies suggest PFMT can be a good therapeutic option for improving UI in elderly women. According to the results that showed the improvement was more prominent in women with SUI, it is concluded that PFMT is necessary especially for gynecologic cancer patients who are more suffering from SUI than UUI as shown in the Table 2. However, qualitative evaluation of UI symptoms by questionnaire might be considered as a limitation of this study. Tosun et al. assessed PFM strength by using vaginal biofeedback and transabdominal ultrasonography and reported significant improvement in muscle strength after training and the pad test for UI showed significantly decreased in PFMT group [34]. Efforts to use the noninvasive and quantitative method to identify the change in pelvic floor muscle after PFMT seems valuable in this study while quantitative assessment tools are deficient. 


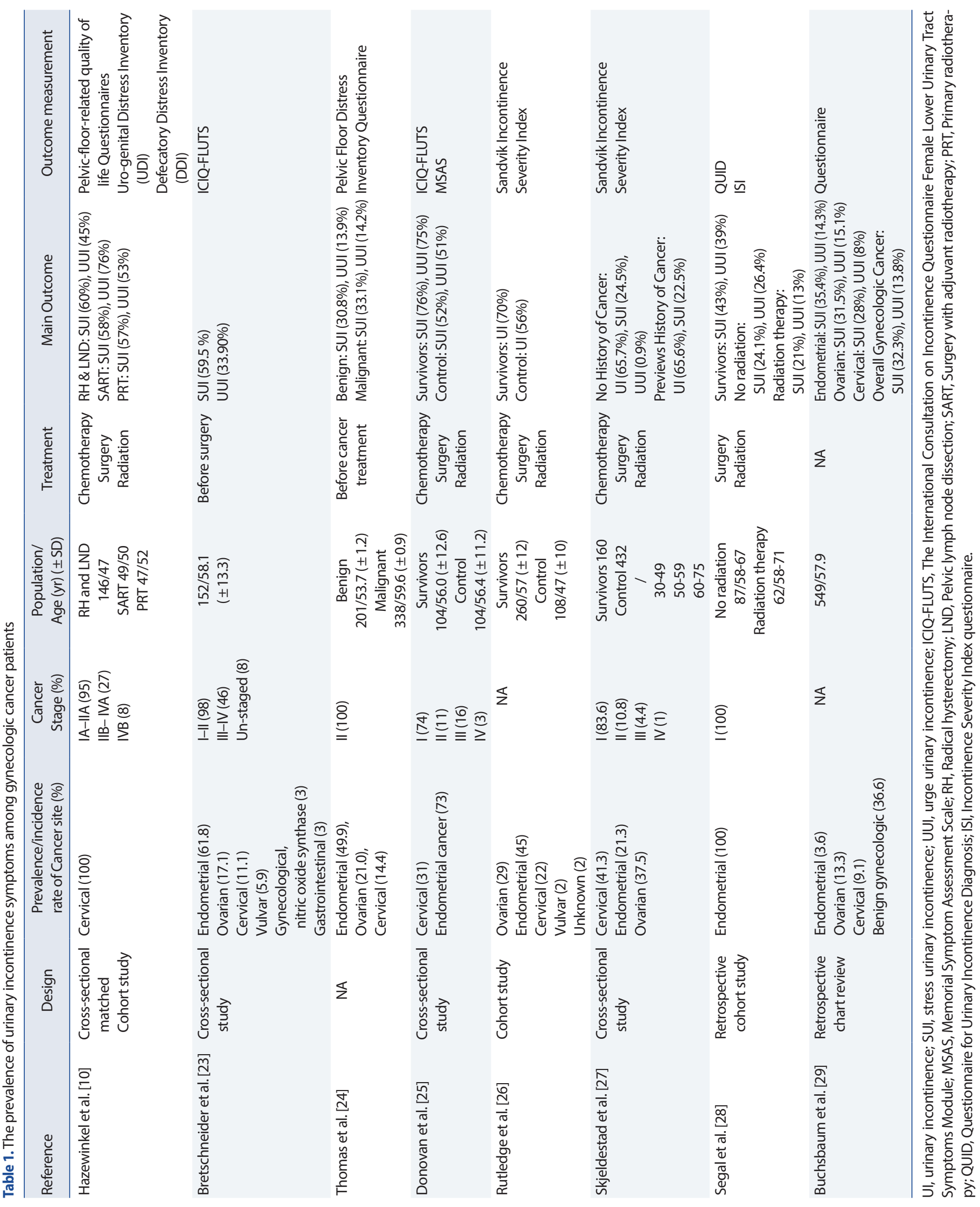


Table 2. A description of pelvic floor muscle training intervention studies with non-gynecologic cancer patient

\begin{tabular}{|c|c|c|c|c|c|c|c|c|}
\hline Reference & Design & $\begin{array}{c}\text { Participants/ } \\
\text { Age } \pm \text { SD }\end{array}$ & $\begin{array}{c}\text { UITypes } \\
\text { (PFMT, CON) }\end{array}$ & PFMT Details & Duration & Frequency & Outcomes & $\begin{array}{c}\text { PEDro } \\
\text { scale }\end{array}$ \\
\hline Castro et al. [30] & RCT & $\begin{array}{l}\text { PFMT-CON } \\
(26,24) / \\
(56.2 \pm 12.5 \\
52.6 \pm 11.2)\end{array}$ & SUI $(26,24)$ & $\begin{array}{l}10 \text { reps } 5 \text { sec contraction } \\
5 \text { sec recovery } 20 \text { reps } \\
1 \text { sec contraction } 1 \mathrm{sec} \\
\text { relax each interval } 5 \text { reps } \\
10 \text { sec contraction } 10 \mathrm{sec} \\
\text { relax } 5 \text { reps strong } \\
\text { contraction }\end{array}$ & 6 months & 3/weeks & $\begin{array}{l}\text { Pad test } \downarrow, \mathrm{I}-\mathrm{QOL} \uparrow, \\
\text { Satisfied after treatment } \\
\text { PFMT } 58 \%, \\
\text { CON } 21 \%\end{array}$ & 8 \\
\hline Cavkaytar et al. [31] & RCT & $\begin{array}{l}\text { SUI-MUI } \\
(38,34) / \\
(49.6 \pm 8.1 \\
48.9 \pm 8.8)\end{array}$ & $\begin{array}{l}\text { SUI }(38,0) \\
\text { MUI }(0,34)\end{array}$ & $\begin{array}{l}10 \text { sets } \\
10 \text { reps } \\
\text { (not well described) }\end{array}$ & 8 weeks & Daily & $\begin{array}{l}\text { IIQ-7 } \uparrow, \text { UDI-6 } \uparrow \text {, } \\
\text { Self-report improvement } \\
\text { SUI: } 68.4 \% \text {, } \\
\text { MUI: } 41.2 \%\end{array}$ & 4 \\
\hline Kim et al. [32] & RCT & $\begin{array}{l}\text { PFMT-CON } \\
(61,63) / \\
\text { over } 70\end{array}$ & $\begin{array}{l}\text { SUI }(19,18) \\
\text { UUI }(22,25) \\
\text { MUI }(22,21)\end{array}$ & $\begin{array}{l}10 \text { reps } 3 \text { sec contraction } \\
5 \text { sec interval rest, } \\
8-10 \text { sec contraction with } \\
10 \text { sec rest each In } \\
\text { different body position }\end{array}$ & 3 months & 2/weeks & $\begin{array}{l}\text { Urine leakage cure rates } \\
\text { PFMT } 44.1 \% \\
\text { CON } 1.6 \%\end{array}$ & 9 \\
\hline Tosun et al. [34] & $\mathrm{RCT}$ & $\begin{array}{l}\text { PFMT-CON } \\
(65,51) / \\
(51.7 \pm 9.7 \\
49.6 \pm 7.6)\end{array}$ & $\begin{array}{l}\text { SUI }(27,21) \\
\text { UUI }(23,17) \\
\text { MUI }(15,13)\end{array}$ & $\begin{array}{l}\text { 2-7 sets Maximal volun- } \\
\text { tary contraction (not well } \\
\text { described) }\end{array}$ & 12 weeks & $\begin{array}{l}\text { 2/weeks } \\
\text { practiced in } \\
1-3 \text { weeks with } \\
\text { physiotherapist } \\
\text { \& daily }\end{array}$ & $\begin{array}{l}\text { Pad test } \downarrow: \\
\text { PFMT/CON }(-2.9 / 0.2) \\
\text { Stop test } \downarrow: \\
\text { PFMT/CON }(-11.7 / 0.3) \\
\text { TAUS } \uparrow: \\
\text { PFMT/CON } \\
(5.1,7.2 /-1.5,1.3) \\
\text { PERFECT test } \uparrow: \\
\text { PFMT/CON } \\
(2.7,31.7,7.9,7.1 / \\
0.2,0.1,-0.7,-0.1)\end{array}$ & 7 \\
\hline
\end{tabular}

UI, urinary incontinence; PFMT, pelvic floor muscle training; CON, control; SUI, stress urinary incontinence; UUI, urge urinary incontinence; MUI, mixed urinary incontinence; I-QOL, quality of life questionnaire; IIQ-7, incontinence impact questionnaire; UDI-6, urogenital distress inventory; TAUS, transabdominal ultrasonography; ICIQ-SF, international consultation on incontinence questionnaire-short form.

\section{PELVIC FLOOR MUSCLE TRAINING FOR THE GYNECOLOGIC CANCER PATIENT WITH URINARY INCONTINENCE}

Only two PFMT intervention studies on gynecologic cancer patients were found (Table 3). In the study by Yang et al. [35] patients who had radical hysterectomy and pelvic lymph node dissection were recruited to participate in the pelvic floor rehabilitation program once a week for four weeks. Unlike other studies, this study focused on patients who underwent surgery as a cancer treatment. Additional studies should be continued to identify PFMT effects by differentiation cancer treatment methods such as radiotherapy and chemotherapy. Of many variables, only pelvic floor strength and sexual functioning showed significant improvement.
The reason for this result may be influenced by the intervention period which was short to accommodate study feasibility and to verify the effects of exercise. A large scale of intervention with a sufficient study period is necessary. Another pilot study demonstrated PFMT program in combination with behavioral therapy for 12 weeks [36]. Although results did not show the superiority of PFMT on behavioral therapy in the improvement of UI, this study was a rare evidence that PFMT to the gynecologic patient.

\section{RESULT AND DISCUSSION}

Through this review, we found that urinary incontinence following gynecologic cancer treatment appeared as a significant adverse effect. 
Table 3. A description of pelvic floor muscle training intervention studies for gynecologic cancer patients

\begin{tabular}{|c|c|c|c|c|c|c|c|c|c|c|}
\hline Reference & Design & $\begin{array}{c}\text { Participants/ } \\
\text { Age } \pm S D\end{array}$ & Cancer Types & $\begin{array}{l}\text { FIGO } \\
\text { Stage }\end{array}$ & Treatment & $\begin{array}{l}\text { PFMT } \\
\text { Details }\end{array}$ & Duration & Frequency & Outcomes & $\begin{array}{l}\text { PEDro } \\
\text { Scale }\end{array}$ \\
\hline $\begin{array}{l}\text { Yang } \\
\text { et al. [35] }\end{array}$ & $\begin{array}{l}\text { Pilot } \\
\text { RCT }\end{array}$ & $\begin{array}{l}\text { PFMT-CON } \\
(12,12) \\
/(52.3 \pm 5.2 \\
52.5 \pm 2.9)\end{array}$ & $\begin{array}{l}\text { Cervical }(13,13) \\
\text { Endometrial }(1,1)\end{array}$ & $\begin{array}{c}\text { I-II } \\
(10,11) \\
\text { III } \\
(4,3)\end{array}$ & $\begin{array}{l}\text { Surg }(1,1) \\
\text { Surg+Radio }(4,4) \\
\text { Surg+Chemo }(6,5) \\
\text { Surg+Radio+ } \\
\text { Chemo }(3,4)\end{array}$ & $\begin{array}{l}40 \text { cycles with } 10 \mathrm{sec} \\
\text { activity followed } \\
\text { by } 20 \mathrm{sec} \text { relaxation }\end{array}$ & $\begin{array}{l}\text { (post) } \\
\text { 4-week }\end{array}$ & $\begin{array}{l}\text { Once a } \\
\text { week, } \\
45 \mathrm{~min} \\
\text { per } \\
\text { session }\end{array}$ & $\begin{array}{l}\text { PFM strength } \uparrow, \\
\text { Sexual function } \uparrow,\end{array}$ & 9 \\
\hline $\begin{array}{l}\text { Rutledge } \\
\text { et al. [36] }\end{array}$ & $\begin{array}{l}\text { Pilot } \\
\text { RCT }\end{array}$ & $\begin{array}{c}\text { PFMT-CON } \\
(20,20) \\
/ 57 \\
\text { (range: } 37-79)\end{array}$ & $\begin{array}{l}\text { Uterine }(14,10) \\
\text { Ovarian }(3,6) \\
\text { Cervical }(2,3) \\
\text { Other }(1,1)\end{array}$ & NA & $\begin{array}{l}\text { Surg }(19,19) \\
\text { Radio }(3,4) \\
\text { Chemo }(7,7) \\
\text { Prior incontinence } \\
\text { treatment }(2,4)\end{array}$ & $\begin{array}{l}10 \text { pelvic muscle } \\
\text { contraction for } \\
5 \mathrm{sec} 3 \text { sets }\end{array}$ & $\begin{array}{c}\text { (post) } \\
\text { 12-week }\end{array}$ & Daily & $\begin{array}{c}\text { Brink's score } \uparrow: \\
\text { PFMT/CON } \\
\text { (mild6.5, } \\
\text { severe-6/ } \\
\text { mild2, sever-2) } \\
\text { PGI-I } \uparrow: \\
\text { PFMT/CON } \\
\text { (80\%/40\% } \\
\text { "much better") }\end{array}$ & 7 \\
\hline
\end{tabular}

FIGO, international federation of gynecology and obstetrics; PFMT, pelvic floor muscle training; CON, control; PGI-I, patient global impression of improvement.

Among the types of urinary incontinence, SUI was the most common one, followed by UUI. The studies which were covered in this review were based on a questionnaire. Thus, it is a major limitation of current evidence that makes it impossible to compare the outcomes of research statistically. Moreover, there is a lack of studies to figure out what kind of treatment and cancer site specifically might induce urinary incontinence. Future studies should focus on the investigating association of cancer stage, site and type of treatment with UI in gynecologic cancer patients; and, quantitative evaluation of UI such as a pad test should be performed together with a validated questionnaire. So far, the effects of PFMT in SUI and UUI have been proved in many studies in non-gynecologic cancer. To our knowledge, only two pilot studies investigated the effects of PFMT in gynecologic cancer survivors which resulted to alleviate UI. According to evidence, PFMT had a beneficial effect on controlling bladder and improvement of urinary in gynecological cancer patients as well. In order to have a better result of the training, effects of PFMT on specific gynecologic cancer (e.g. cervical, ovarian etc.) should be concerned. Thus, more research on PFMT exercise intervention study is needed to define the proper frequency, intensity, time and type of exercise related to gynecologic cancer patients' characteristics.

\section{CONCLUSION}

This present study is the first narrative review study to investigate the prevalence of UI in gynecologic cancer patients and effects of the PFMT to increase control of the bladder which will result alleviate of inconti- nence. This study provides evidence supporting beneficial effects of the PFMT program on improvement of incontinence in non-gynecological cancer subjects and gynecological cancer patients. Thus, we suggest that as a process of rehabilitation of gynecologic cancer patients, the PFMT might be an effective program to treat UI and enhance control of bladder which may improve the overall quality of life in cancer patients.

\section{REFERENCES}

1. Siegel RL, Miller KD, Jemal A. Cancer statistics. CA Cancer J Clin. 2015;65(1):5-29.

2. National Cancer Information Center. Cancer incidence Rates. 2015; Retrieved from: https://www.cancer.go.kr/lay1/S1T639C641/contents. do

3. American Cancer Society. Endometrial Cancer Survival Rates, by Stage. 2018 February 7; Retrieved from: https://www.cancer.org/cancer/endometrial-cancer/detection-diagnosis-staging/survival-rates

4. Miller KD, Siegel RL, Lin CC, Mariotto AB, Kramer JL, et al. Cancer treatment and survivorship statistics. CA Cancer J Clin. 2016;66(4): 271-89.

5. Omichi C, Nakamura K, Haraga J, Ida N, Saijo M, et al. The influence of adverse effects on quality of life of survivors of gynecologic cancer. Int J Gynecol Cancer. 2017;27(9):2014-9.

6. Stabile C, Gunn A, Sonoda Y, Carter J. Emotional and sexual concerns in women undergoing pelvic surgery and associated treatment for gynecologic cancer. Transl Androl Urol. 2015;4(2):169-85. 
7. Bernard S, Moffet H, Plante M, Ouellet MP, Leblond J, et al. Pelvicfloor properties in women reporting urinary incontinence after surgery and radiotherapy for endometrial cancer. Phys Ther. 2017; 97(4):438-48.

8. Pedersen D, Bentzen SM, Overgaard J. Early and late radiotherapeutic morbidity in 442 consecutive patients with locally advanced carcinoma of the uterine cervix. Int J Radiat Oncol Biol Phys. 1994;29(5):94152.

9. Jensen PT, Groenvold M, Klee MC, Thranov I, Petersen MA, et al. Longitudinal study of sexual function and vaginal changes after radiotherapy for cervical cancer. Int J Radiat Oncol Biol Phys. 2003;56(4): 937-49.

10. Hazewinkel MH, Sprangers MAG, Van der Velden J, Van der Vaart $\mathrm{CH}$, Stalpers LJA, et al. Long-term cervical cancer survivors suffer from pelvic floor symptoms: a cross-sectional matched cohort study. Gynecol Oncol. 2010;117(2):281-6.

11. Bernard S, Ouellet MP, Moffet H, Roy JS, Dumoulin C. Effects of radiation therapy on the structure and function of the pelvic floor muscles of patients with cancer in the pelvic area: a systematic review. J Cancer Surviv. 2016;10(2):351-62.

12. Nygaard IE, Kreder KJ, Lepic MM, Fountain KA, Rhomberg AT. Efficacy of pelvic floor muscle exercises in women with stress, urge, and mixed urinary incontinence. Am J Obstet Gynecol. 1996;174(1):120-5.

13. Shafik A, Shafik IA, El Sibai O, Shafik AA. The effect of external urethral sphincter contraction on the cavernosus muscles and its role in the sexual act. Int Urol Nephrol. 2007;39(2):541-6.

14. Kegel AH. Stress incontinence and genital relaxation. Ciba Clin Sympos. 1952;2:35-51.

15. Hirakawa T, Suzuki S, Kato K, Gotoh M, Yoshikawa Y. Randomized controlled trial of pelvic floor muscle training with or without biofeedback for urinary incontinence. Int Urogynecol J. 2013;24(8):1347-54.

16. Marques A, Stothers L, Macnab A. The status of pelvic floor muscle training for women. Can Urol Assoc J. 2010;4(6):419-24.

17. Bø K. Pelvic floor muscle training is effective in treatment of female stress urinary incontinence, but how does it work? Int Urogynecol J. 2004;15(2):76-84.

18. Radzimińska A, Strączyńska A, Weber-Rajek M, Styczyńska H, Strojek $\mathrm{K}$, et al. The impact of pelvic floor muscle training on the quality of life of women with urinary incontinence: a systematic literature review. Clin Interv Aging. 2018;13:957-65.

19. MacDonald R, Fink HA, Huckabay C, Monga M, Wilt TJ. Pelvic floor muscle training to improve urinary incontinence after radical prostatectomy: a systematic review of effectiveness. BJU Int. 2007;100(1):7681.

20. Kannan P, Winser SJ, Fung B, Cheing G. Effectiveness of pelvic floor muscle training alone and in combination with biofeedback, electrical stimulation, or both compared to control for urinary incontinence in men following prostatectomy: a systematic review and meta-analysis. Phys Ther. 2018;98(11):932-45.

21. Han GY, Song W. Practical exercise intervention to reduce adverse effects for prostate cancer patients. Exerc Sci. 2017;26(2):152-8.

22. Mørkved S, Bø K. Effect of pelvic floor muscle training during pregnancy and after childbirth on prevention and treatment of urinary incontinence: a systematic review. Br J Sports Med. 2014;48(4):299-310.

23. Bretschneider CE, Doll KM, Bensen JT, Gehrig PA, Wu JM, et al. Prevalence of pelvic floor disorders in women with suspected gynecological malignancy: a survey-based study. Int Urogynecol J. 2016;27(9): 1409-14.

24. Thomas SG, Sato HR, Glantz JC, Doyle PJ, Buchsbaum GM. Prevalence of symptomatic pelvic floor disorders among gynecologic oncology patients. Obstet Gynecol. 2013;122(5):976-80.

25. Donovan KA, Boyington AR, Judson PL, Wyman JF. Bladder and bowel symptoms in cervical and endometrial cancer survivors. Psycho-oncology. 2014;23(6):672-8.

26. Rutledge TL, Heckman SR, Qualls C, Muller CY, Rogers RG. Pelvic floor disorders and sexual function in gynecologic cancer survivors: a cohort study. Am J Obstet Gynecol. 2010;203(5):514.e1.

27. Skjeldestad FE, Rannestad T. Urinary incontinence and quality of life in long-term gynecological cancer survivors: a population-based crosssectional study. Acta Obstet Gynecol Scand. 2009;88(2):192-9.

28. Segal S, John G, Sammel M, Andy UU, Chu C, et al. Urinary incontinence and other pelvic floor disorders after radiation therapy in endometrial cancer survivors. Maturitas. 2017;105:83-8.

29. Buchsbaum GM, Holly Sato MD, Paula Doyle MD, Thomas S. Prevalence of pelvic floor disorders in various gynecologic cancers. Neurourol Urodyn. 2012;31(6):779-80.

30. Castro RA, Arruda RM, Zanetti MR, Santos PD, Sartori MG, et al. Single-blind, randomized, controlled trial of pelvic floor muscle training, electrical stimulation, vaginal cones, and no active treatment in the management of stress urinary incontinence. Clinics. 2008;63(4): 465-72.

31. Cavkaytar S, Kokanali MK, Topcu HO, Aksakal OS, Doğanay M. Ef- 
fect of home-based Kegel exercises on quality of life in women with stress and mixed urinary incontinence. J Obstet Gynaecol Res. 2015; 35(4):407-10.

32. Kim H, Yoshida H, Suzuki T. The effects of multidimensional exercise treatment on community-dwelling elderly Japanese women with stress, urge, and mixed urinary incontinence: a randomized controlled trial. Int J Nurs Stud. 2011;48(10):1165-72.

33. Lee BA, Kim SJ, Choi DK, Kwon O, Na HR, et al. Effects of pelvic floor muscle exercise on urinary incontinence in elderly women with cognitive impairment. Int Neurourol J. 2017;21(4):295.

34. Tosun OC, Solmaz U, Ekin A, Tosun G, Gezer C, et al. Assessment of the effect of pelvic floor exercises on pelvic floor muscle strength using ultrasonography in patients with urinary incontinence: a prospective randomized controlled trial. J Phys Ther Sci. 2016;28(2):360-5.

35. Yang EJ, Lim JY, Rah UW, Kim YB. Effect of a pelvic floor muscle training program on gynecologic cancer survivors with pelvic floor dysfunction: a randomized controlled trial. Gynecol Oncol. 2012; 125(3):705-11.

36. Rutledge TL, Rogers R, Lee SJ, Muller CY. A pilot randomized control trial to evaluate pelvic floor muscle training for urinary incontinence among gynecologic cancer survivors. Gynecol Oncol. 2014;132(1): 154-8. 